\title{
015 \\ Problems and improvement potentials of Kandyan homegardens at Yatinuwara area
}

\author{
K I A Kothalawala, D K N G Pushpakumara and T Sivananthwerl \\ Department of Crop Science, Faculty of Agriculture, University of Peradeniya, Sri Lanka
}

\begin{abstract}
Kandyan homegardens are the most predominant upland cropping system which supposed to be highly adapted, diversified. economically and environmental viable land use system. Objectives of this study were to identify problems and improvement potentials to this important system of land management. Data were collected from randomly selected $(n=65)$ homegardens in Yatinuwara District Secretariat division during 2006. A vegetation survey was conducted to evaluate the structure and composition of homegardens. A household survey was conducted by interviewing the members to identify tree use practices by family members, constraints and improvement potentials. Secondary data were also collected from Agrarian Service Centres, maps and reports.
\end{abstract}

Homegardens in the study area have maintained diverse on farm trees. They cultivating and using at least 138 species of which 36,34,24 and 6\% comprised timber, medicinal plant, fruit tree and export agricultural crop species. There are $73,193,300$ and 147, individuals of timber, fruit. medicinal and export agricultural crops plants/ha indicating high plant density per unit area. These species grown on homegardens have substantially contributed to meet the daily need of household, supplying mainly fruit, green vegetable, timber and fuelwood. Some of these species have medicinal value and also play an important role in soil conservation. This suggests that homegardens are important as a source of conserving agro-biodiversity, species, habitat and landscape protection. However, more than half of the homegardens of Yatinuwara area are 20-80 perches category which indicate land fragmentation. Thus, each land unit has to play a vital role with limited land availability. Therefore, sustainable management practices are very important to increase production to reach increasing demand due to increasing human population while maintaining the resource base. In satisfying necessary changes to homegardens, availability of quality planting material (only $22 \%$ had access to recommended planting material), height of fruit trees, poor soil management and labour scarcity were identified as major problems in Yatinuwara area. There are improvement potentials to homegardens by increasing the productivity of the existing system. It is possible even to increase the number of trees per homegardens by introducing new varieties. It is also possible to replace existing less productive individuals by certified planting material. In addition, management of soil can also be improved by introducing new techniques such as compost preparations with garbages and fallen leaves which require attitudinal changes of households. Implications of these are discussed with respect to food, nutritional and health security and income generation.

\section{$\underline{016}$ \\ Agro- forestry system to protect both the Sinharaja forest and the peripheral villages (a case study of the southern part of Sinharaja)}

\author{
H I G C Kumara
}

Department of Geography, University of Ruhuna, Sri Lanka

Sinharaja, a 'Tropical Wet Ever Green Rain Forest' situated between latitude $6^{\circ} 21^{\prime}-6^{\circ} 26^{\prime} \mathrm{N}$ and longitude $80^{\circ} 31^{\prime}-80^{\circ} 34^{\prime} \mathrm{E}$ in Sri Lanka is surrounded by more than 27 peripheral villages. The villagers have interacted with the forest for many years. The objective of this study is to verify the aptness of introducing the Agro-forestry System into these peripheral villages to protect both the forest and the villages. The villages situated in the southern part of Sinharaja namely, Kosmulla, Thabalagama, Madugeta, Warukandeniyaa and Kollonthotuwa were selected for primary-data collection. Participatory observation approach is basically used while adhering to the secondary and tertiary data as well. According to study there is a traditional yet unorganized agro-farming system among these villagers. So, many cultivated creepers varieties and tree species can be seen in the yards. Also, for years the villagers have used the forest for many purposes. Thus, when the villagers encroach forest the forest tends to decline. Also, due to mono- crop cultivation, especially tea, quality

Proceedings of the International Forestry and Environment Symposium 2006 of the

Department of Forestry and Environmental Science. Lniversity of Sri Jayewardenepura. Sri Lanka 
of soil diminishes and tea cultivation has caused many environmental problems. Thus, stabilization of a systematic Agro- forestry system in these areas would minimize the environmental problems and would conserve both 'Sinharaja' and its peripheral villagers. Further, this kind of stabilization process should go parallel with the prevalent lifestyles and culture of the villagers. Additionally, that process should provide villagers with economical advantages. Moreover, plantation of crop verities in the tea lands should be encouraged as well as animal husbandry, apiculture and plantation of medicinal plant etc. Yet, the contribution and the sponsorship of the government and non-government organizations, plan and policy making of scientists and the active participation of the peripheral villagers are essential to bring these activities into success.

\title{
$\underline{017}$ \\ Behaviour of cattle in an agro-forestry system \\ D Senaratna, N S B M Atapattu, W G D, Lakmini, W I R Palihakkara, B Piyadigama and C C Senaratne Department of Animal Science, University of Ruhuna, Sri Lanka
}

Objective of the present study was to understand the behaviour of dairy cattle tethered under agro-forestry systems. Three genetically uncharacterized, indigenous, non-lactating cows and two bulls (mean live weight $199 \pm 29$ ) were tethered close to a water stream in an agro-forestry system. The vegetation of the agro-forestry system comprised of teak, coconut, mahogany and shrubs. Animals had enough foraging materials around the place they were tethered. One observer was assigned to each animal. The behaviour of the animals was observed for five hours from $10001500 \mathrm{hrs}$. The mean temperature and the relative humidity of day of the study were $28^{\circ} \mathrm{C}$ and $79 \%$ respectively. Frequency and the duration of the time spent on nine behaviours were recorded. The behavioural activities studied were drinking, feeding (ground level and upper level), lying, standing, walking, urination, defecation, vocalization and interactions (cattle-cattle and cattle-other animals). Feeding was the most prominent behaviour of the animals. The time spent on feeding and the frequency of feeding during the 300 minutes study period were $252 \mathrm{~min}$ and 23 , respectively and thus the feeding behaviour accounted for $84 \%$ of the total time budget. The frequency (15) and the time spent on ground level grazing $(234 \mathrm{~min})$ were significantly higher $(p<0.001)$ than the frequencies and the time spent on upper level feeding. Though not statistically significant, animals spent more time on standing (18.9 min or $6.3 \%$ of the total time) than on Laying (14.6 min or $5 \%$ of the total time). The frequency of standing (5) was also significantly $(\mathrm{p}<0.001)$ higher than that of lying (1). May be due to tethering, cattle spent less time ( 8.3 minutes or $2.7 \%$ of the total time) on walking. The frequency of drinking (2) and the time spent on drinking were ( $3 \mathrm{~min}$ or $1 \%$ of the total time) unexpectedly low. Cattle defecated and urinated twice during the five- hour study period. Vocalization was the least prominent behavioural activity. It is concluded that cattle highly engage with feeding particularly, on ground level when they are tethered under agro-forestry systems. Further researches are needed to determine as to why the drinking behaviour is suppressed when tethered in agro-forestry systems.

\section{$\underline{018}$}

\section{Design and development of power tiller operated multipurpose whole stick harvester especially for sugarcane}

\author{
P L A G Alwis, L W S Pemasiri and W S K Rathnayake \\ Faculty of Agriculture, University of Ruhuna, Mapalana, Kamburupitiya, Sri Lanka.
}

In Sri Lanka cane harvesting is done manually using various types of hand knives. This method of harvesting not only consumes much time but also requires much skilled labourers. But nowadays labourers are becoming scarce and costly, particularly in sugarcane cultivation areas. This is due to diversion of labour to other more remunerative work in industry, construction, business and diversion of labour to other crops.

It is difficult to employ heavy machines in Sri Lanka due to various reasons such as, fragmented and small holdings with small and irregular fields, diverse cropping patterns followed, the cultivation practices

Proceedings of the International Forestry and Environment Symposiam 2006 of the 